\title{
Inflammatory Manifestations of Systemic Diseases in the Central Nervous System
}

\author{
David A. Lapides, $M D^{*}$ 。 \\ Mark M. McDonald, MD, MS
}

\author{
Address \\ "Division of Neuroimmunology, Department of Neurology, University of Virginia, \\ 1222 Lee Street, Charlottesville, VA, 22908, USA \\ Email: dlapides@virginia.edu
}

Published online: 29 July 2020

(C) Springer Science+Business Media, LLC, part of Springer Nature 2020

This article is part of the Topical Collection on Neurologic Manifestations of Systemic Disease

Keywords Sjogren's syndrome · Neurobehcet's disease · Systemic lupus erythematosus · Immune checkpoint inhibitors

\begin{abstract}
Purpose of Review This review presents the current recommended therapeutic interventions for inflammatory disease in the central nervous system (CNS) secondary to systemic diseases of immune dysregulation. Treatment recommendations for CNS inflammation associated with rheumatologic conditions, immune-related adverse effects from immune checkpoint inhibitors (ICIs), and demyelinating disease from tumor necrosis factor- $\alpha$ (anti-TNFs) are explored. Additional therapeutic options for inflammation related to postviral syndromes and genetic immunodeficiencies are also discussed.

Recent Findings In addition to treatment of mild, moderate, and severe CNS rheumatologic disease as guided by the European League Against Rheumatism (EULAR), early consideration of rituximab for severe IgG4-related disease and induction with anti-TNF therapy for severe neurosarcoidosis should be considered. Although often not first line, treatment options for CNS inflammatory diseases based on disease mechanism are emerging, including tocilizumab for Behcet's disease, natalizumab for ICI associated autoimmune encephalitis, and abatacept for treatment of infiltrative disease secondary to CTLA-4 deficiency. Hematopoietic stem cell treatments represent highly efficacious but risky options for autoimmunity related to genetic immunodeficiency.

Summary While early high dose steroids remains first line therapy for most CNS inflammatory conditions, a rapidly expanding arsenal of immune targeted therapies offers clinicians tailored disease specific options for treatment.
\end{abstract}




\section{Introduction}

Inflammation in the central nervous system (CNS) can occur by multiple mechanisms including cytokine-mediated inflammation, antibodymediated demyelination, immune cell infiltration, mass-like formation, granulomatous inflammation, $\mathrm{T}$ cell-mediated cytotoxic injury, and vasculitic inflammation [1]. While there are a number of autoimmune inflammatory diseases which are largely restricted to the CNS, many under recognized systemic diseases also lead to inflammatory presentations. Early identification of the underlying etiology of neurological disease is essential as unchecked inflammation can cause severe neurological disability or even death. Furthermore, proper diagnosis can facilitate a therapeutic approach targeting disease specific mechanisms.
In this review, we report on treatment recommendations for four classes of CNS inflammation resulting from systemic disease: (1) rheumatologic diseases with CNS involvement, (2) inflammatory adverse effects of common pharmacological therapies, (3) postviral inflammatory syndromes, and (4) autoimmune diseases resulting from immunodeficiency syndromes.

Notably, autoimmunity in the setting of immunodeficiency is an area of emerging diagnostic and therapeutic value. Genetically identified disease mechanisms drive targeted immunotherapy which may translate into future treatment for other disorders. Given the vast number of inflammatory mechanisms, we have had to restrict the scope of our manuscript and treatment for inflammation secondary to infectious, neoplastic, or proliferative diseases will not be covered.

\section{Inflammation of the Central Nervous System from Rheumatologic Disorders}

Sjogren's syndrome (SS) is an autoimmune disease which manifests as lymphocytic and plasmacytic infiltration into exocrine glands $[2 \bullet, 3]$. The CNS is involved in $\sim 6 \%$ of SS patients and neurologic symptoms precede systemic symptoms in over half of cases [4,5]. Typically, CNS involvement manifests as multiple sclerosis (MS)-like lesions in the brain, longitudinally extensive transverse myelitis (LETM), cranial neuropathies, vasculitis, aseptic meningitis, encephalitis, and cerebellar ataxia [3,4,6,7]. Notably, while patients may meet criteria for SS, it is essential to test for aquaporin$4 \mathrm{IgG}$ and myelin oligodendrocyte glycoprotein (MOG) IgG as CNS involvement in SS is often related to concurrent neuromyelitis optica spectrum disorder (NMOSD) $[7,8]$.

The evidence for treatment of CNS disease in SS is limited and should be tailored to disease severity as defined by the EULAR (European League Against Rheumatism) Sjogren's syndrome disease activity index (ESSDAI) $[1,9 \bullet 10]$. Typical first-line therapy for severe inflammatory presentation includes highdose intravenous methylprednisolone, $1000 \mathrm{mg}$ daily for 3-5 days, followed by a course of oral prednisone, $0.5-1 \mathrm{mg} / \mathrm{kg} /$ day tapered over weeks to months $[1,4,11]$. Plasmapheresis (PLEX) combined with steroids may be an effective approach for LETM and also represents rational empiric therapy given NMO overlap potential [12]. The 2020 EULAR SS guideline recommends cyclophosphamide and PLEX+rituximab as second-line and third-line therapy, respectively, for severe CNS involvement but breakthrough disease is common (level IV) [11]. Notably, however, for MS-like presentations, MS disease-modifying therapy should be employed (level V) [९•]. 
Systemic lupus erythematosus (SLE) is a connective tissue disease characterized by multiorgan inflammation $[2 \bullet, 3,13]$. Neuropsychiatric SLE (NPSLE) may occur in up to $40 \%$ of SLE patients [14]. Inflammatory disease specifically may manifest as a demyelinating disease similar to MS or NMOSD with cerebral and cord lesions or pachymeningitis, although clinically patients may present with psychosis, seizures, or encephalopathy $[15,16]$. Patients may also suffer strokes in the presence of antiphospholipid (APL) antibodies [1,15-18]. CSF shows lymphocytic or polymorphonuclear pleocytosis without oligoclonal bands [15].

Inflammatory disease treatment is tailored to disease severity and managed with steroids and immunosuppression, whereas vascular manifestations are treated with anticoagulation/anti-thrombotics. Notably, the two processes may be difficult to distinguish and may even coexist in a single patient. Hydroxychloroquine is appropriate for all patients with SLE, not to exceed $5 \mathrm{mg} / \mathrm{kg} /$ day (grade A) [19•]. For patients with severe CNS disease e.g. cerebritis or myelitis, treatment with IV steroids is first line, e.g., methylprednisolone $1000 \mathrm{mg}$ for 3 days followed by oral steroids, such as prednisone $1 \mathrm{mg} / \mathrm{kg} / \mathrm{day}$ (grade A) [19•].

Induction with pulse cyclophosphamide for 3-6 months in severe disease has shown long-term efficacy and safety (grade C) $[16,19 \bullet, 20]$. For maintenance, azathioprine and mycophenolate mofetil can be used after induction to taper steroids to the lowest tolerated level, continuing treatment for $>$ 12 months minimum to prevent relapse (Grade C) $[16,19 \bullet, 20]$. Rituximab is recommended for disease breakthrough activity, although in our center, it is used for maintenance as well [19•]. Breakthrough disease may also respond to IVIG or PLEX $[1,16,20]$. Notably, for moderate SLE, belimumab, a monoclonal antibody that reacts with B cell-activating factor or BAFF, shows promising disease response, although patients with severe NPSLE were excluded from these studies (grade A) [16].

In SLE with APL antibodies, there is no evidence for primary stroke prevention [15]. However, if CNS injury is favored to be ischemic, treatment for acute stroke is standard of care, tissue plasminogen activator (tPA), and/or thrombectomy [19•]. For secondary stroke prevention, either aspirin or warfarin can be used, and novel oral anticoagulants can be considered if warfarin is contraindicated $[15,21]$. Notably, for recurrent stroke without APL or vascular risk factors, immunosuppression may be warranted [19•].

Behcet's disease (BD) is a multisystemic immune-mediated vasculitis characterized by recurrent mucocutaneous ulceration involving the mouth and genitals. BD impacts the CNS in $5-10 \%$ of cases $[1,2 \bullet]$. Neurobehcet's (NBD) is divided into parenchymal and non-parenchymal (vascular) subtypes. The most common manifestation of parenchymal disease is meningoencephalitis presenting as headache, cognitive impairment, sensory and motor dysfunction, and/or psychosis [2•]. Central venous sinus thrombosis (CVST) is the most frequent form of non-parenchymal disease; however, stroke due to arterial thrombosis or vasculitis also occur $[2 \bullet, 22]$. Cerebrospinal fluid (CSF) studies initially show neutrophilic pleocytosis with potential shift to lymphocyte predominance with elevated protein, negative OCBs, and elevated IL-6 $[2 \bullet, 23]$. 
For parenchymal disease, treatment with $1 \mathrm{~g}$ methylprednisolone for 57 days is first line, along with oral steroid taper $(1 \mathrm{mg} / \mathrm{kg} /$ day $)$ and an immunosuppressive agent [24]. For moderate disease, azathioprine or mycophenolate mofetil are recommended $[24,25]$. For severe parenchymal NBD, TNFalpha antagonists, such as infliximab should be considered for first line and breakthrough disease (level III, grade C) $[24,25]$. Given the finding of elevated CSF IL-6, tocilizumab has also been trialed and shown promising efficacy [2628]. Cyclosporine should be avoided due to neurotoxicity [22,24].

For non-parenchymal disease with CVST, first-line therapy is also high-dose steroids with an oral taper but further immunosuppression is not usually necessary as relapses are uncommon [24]. Use of anticoagulation is debated given increased risk of bleeding, but a short course is advised (Grade C) $[22,25,26]$. Recurrence of CVST is rare if systemic inflammation is well controlled, and accordingly, long-term anticoagulation is not indicated [24,25]. Similarly, recurrence of dissection in the setting of vasculitis may be prevented with early pulse steroids [29].

Rheumatoid arthritis (RA) is an inflammatory disorder characterized by joint deformation, synovitis, and erosive arthritis $[2 \bullet, 3]$. In RA, activated monocytes and lymphocytes infiltrate the joints, skin, eyes, lung, blood vessels, and even the nervous system [30]. Compressive myelopathy is the most common CNS manifestation while leptomeningitis, encephalitis, and CNS vasculitis can also occur, albeit such brain involvement in RA is rare [31,32]. Less than half of patients with CNS disease have active synovitis and 34\% of patients had no history of RA prior to diagnosis [33]. The most common brain MRI finding is nodular patchy or lepto-meningeal thickening and enhancement, and biopsy is the gold standard for diagnosis $[2 \bullet, 34]$.

Given that CNS disease in RA is relatively rare, evidence for therapy efficacy is limited to case series and expert opinion [1,31]. Acute compressive myelopathy is most commonly treated with surgical intervention along with IV steroids [1]. The recommended acute therapy for CNS vasculitis is high-dose IV steroids and cyclophosphamide [1,35-37]. For RA-associated leptomeningitis, steroids are the most common initial treatment, but roughly $50 \%$ of patients will not respond to steroids alone $[1,35,38]$. Case studies support the use of either cyclophosphamide or rituximab [38]. Anti-TNF agents should not be employed as they may be ineffective and increase CNS disease activity [34]. Conclusive data is lacking regarding the efficacy of methotrexate for CNS involvement of RA [2•]. As far as the consideration of maintenance therapy, it is important to note that the recurrence of RA meningitis is rare [38]. In addition to diseasemodifying therapy, there is evidence that the transient neurological deficits in RA meningoencephalitis should be treated with antiepileptic drugs (AEDs). Even episodes that are not clearly electroclinical seizures seem to respond to AED's $[34,39]$.

Sarcoidosis is an autoimmune disease associated with granulomatous inflammation that can present in almost any organ system [2•]. While sarcoidosis affects the PNS more often, common CNS presentations include cranial 
neuropathies, headache, meningismus due to leptomeningeal infiltration, myelopathy, and seizures $[2 \bullet]$.

Evidence for treatment of neurosarcoidosis (NS) is based on cases series and expert opinion [40•, 41-43]. For mild presentations, oral prednisone, $1 \mathrm{mg} / \mathrm{kg}$ can be initiated with a slow taper over months. Steroid monotherapy fails in $80 \%$ of cases due to disease progression and/or toxicity $[40 \bullet, 41]$. For severe disease, IV solumedrol $1000 \mathrm{mg}$ daily for 3-5 days should be initiated, followed by oral taper $1 \mathrm{mg} / \mathrm{kg}$ over months to years with a steroid sparing agent (SSA). While methotrexate, azathioprine, mycophenolate mofetil, and cyclophosphamide are all used to wean steroids, methotrexate has shown to be more effective than mycophenolate mofetil at preventing relapses, along with a higher risk of side effects (class IV) $[40 \bullet, 42]$.

More recently, infliximab has emerged as an effective treatment for NS after a case series in patients treated with an additional SSA found that $77 \%$ of patients had clinical improvement and $28 \%$ of these patients had complete neurological recovery after treatment with infliximab (class IV) [40•]. Infliximab or adalimumab may be used as an induction agent for severe disease in place of IV steroids, after IV steroids as a bridge to an alternative oral agent as a maintenance therapy itself.

Anti-neutrophil cytoplasmic antibody (ANCA)-associated vasculitis (AAV) is a class of small and medium vessel vasculitidies that affect multiple organ systems including the CNS $[44 \bullet, 45]$. AAV includes granulomatosis with polyangiitis (GPA), microscopic polyangiitis (MPA), and eosinophilic granulomatosis with polyangiitis (EGPA) [44•]. AAV can cause CNS injury either through inflammation of the small and medium sized cerebral vessels or via extravascular granuloma formation $[44 \bullet, 45]$. The most common CNS manifestation is hypertrophic pachymeningitis but posterior reversible encephalopathy syndrome (PRES), parenchymal mass lesions, and ischemic and hemorrhagic stroke can also occur $[44 \bullet, 45]$. The ANCA immunoassay is highly specific in the appropriate clinical context but can be negative in up to half of patients with GPA and MPA $[44 \bullet]$. Biopsy of meningeal and parenchymal tissue is the gold standard of diagnosis $[44 \bullet, 45])$.

General guidelines for acute treatment of AAV depend on whether a clinical attack is considered "organ-threatening" [44•]. CNS involvement generally constitutes classification as organ-threatening or severe and initial treatment includes a combination of high dose steroids and cyclophosphamide $[44 \bullet, 45]$. Rituximab is equivalent to cyclophosphamide for acute treatment and superior as a maintenance therapy (level II) [46]. However, some experts still recommend that rituximab should only be used as acute treatment if there is a contraindication to cyclophosphamide [45]. Maintenance therapy for 2 years is recommended, and such regimen should include low-dose oral steroids and an immunosuppressive agent, e.g., rituximab, azathioprine $(\mathrm{AZA})$, or mycophenolate mofetil [44•]. For systemic AAV, AZA has been shown to be superior to MMF [47]. Methotrexate, dosed at $0.3 \mathrm{mg} / \mathrm{kg} /$ day, is another option for maintenance [45]. 
IgG4-related disease (IgG4-RD) manifests as plasma cell infiltration into almost any organ with histopathologic findings of lymphoplasmacytic infiltration and storiform fibrosis in the setting of a high ratio of IgG-4-positive plasma cells [48-50]. Systemically, patients present with diffuse masses or swelling in organs concerning for malignancy, but IgG4-RD hypertrophic pachymeningitis is characterized by the lack of other organ involvement $[50,51]$. Patients may also demonstrate isolated or concomitant spinal cord disease, either masses, spinal dural enhancement, or transverse myelitis [51,52]. CSF may show IgG4 10x normal level even though 56\% of cases show normal serum IgG4 [50-52].

A treatment algorithm for isolated hypertrophic pachymeningeal disease has been proposed which begins with decompression of the inflammatory mass if there is adjacent structure compression [51]. Intravenous solumedrol, $1000 \mathrm{mg}$ daily for 3-5 days is recommended first line therapy followed by an oral taper of $1 \mathrm{mg} / \mathrm{kg} /$ day prednisone. If disease is mild, steroid monotherapy may be effective, but in general immunosuppressive therapy with azathioprine, mycophenolate mofetil or methotrexate are used without supporting evidence [2•]. For severe neurological disease or neurological and systemic disease involvement, steroids with rituximab is recommended for induction and maintenance $[2 \bullet, 53]$. If a patient relapses, intravenous or oral cyclophosphamide should be considered for induction [51].

\section{Inflammatory Disease in the CNS Secondary to Therapeutic Medications}

\section{Immune Checkpoint Inhibitors: Immune-Related Adverse Effects}

Immune checkpoint inhibitors (ICIs), most commonly those targeting cytotoxic T lymphocyte antigen-4 (CTLA-4) and programmed cell death 1 pathway (PD-1) or its ligand programmed cell death ligand 1 (PD-L1), are now used for a variety of cancer treatments including melanoma, lymphoma, renal cell carcinoma, and cancer of the bladder, liver, gastro-esophagus, lung and squamous cell cancer of the head and neck [54-58]. These immune checkpoints function to provide natural immune system homeostasis by inhibiting $\mathrm{T}$ cell activation. When blocked, increased immune system activity can result in a host of immune-related adverse events (irAEs) including inflammation in the central nervous system [59]. Cases of neurological autoimmunity are estimated around $1 \%$; however, those with personal history of autoimmune disease are at higher risk of developing side effects $[60,61 \bullet]$. Symptoms usually start within weeks to months, but we have seen CNS presentations up to 2 years after treatment initiation.

The most common CNS irAEs are autoimmune encephalitis (AE) and meningitis, but posterior reversible encephalopathy syndrome (PRES), demyelination, exacerbation of MS, and even sarcoidosis have been reported [61 $\bullet, 62-$ 65]. Regarding $\mathrm{AE}$, it may present alongside malignancies not commonly associated with spontaneous $\mathrm{AE}$ and most often no antibodies are found in serum or CSF. When neural auto-antibodies are identified, a patient's syndrome may follow the typical phenotype. Aseptic meningitis, most commonly associated with treatment after ipilimumab, an anti PD-1 ICI, may occur in as many as $0.1-0.2 \%$ of treated patients $[60,66]$. 
Regarding treatment of ICI associated AE, while there are fatal cases in this complex patient population, it is most often exquisitely steroid sensitive. Initially, empiric treatment for infectious etiologies is appropriate, as $\mathrm{AE}$ is a diagnosis of exclusion and appropriate symptom management including seizure control is essential [67].

For medically significant or life threatening irAE (grade 3 or 4 ), treatment with high-dose intravenous (IV) methylprednisolone is recommended for 35 days $[60,61 \bullet, 67]$. Of note, there are no clinical studies regarding treatment recommendations and experts may disagree on duration of IV steroids and the need for additional prolonged immune suppression. If a patient improves, a prolonged 6-8-week oral steroid taper is recommended along with a year of immunosuppression. If there is limited or no clinical response, clinicians should consider plasma exchange, intravenous immunoglobulin (IVIg), cyclophosphamide, rituximab, azathioprine, or methotrexate [60]. If these treatments do not lead to symptomatic improvement, anti-IL17 therapies, bortezomib, infliximab, tacrolimus, or mycophenolate mofetil can be considered [60].

Natalizumab has also been published as an effective therapy in a patient with AE [68]. Decreasing leukocyte crossing into the CNS is theorized to be an effective management strategy to allow for ICI to continue systemic effect while preventing access to the CNS.

If a patient's symptoms are milder, grade 1 or 2 irAE, oral steroids should again be considered $0.5-1 \mathrm{mg} / \mathrm{kg}$ for 7 days followed by observation or $6-8$ week oral steroid taper. Most experts agree to discontinue an ICI if a moderate to severe grade 2-4 neurological irAE occurs; however, if an immune-related adverse event occurs with an ICI, it still may be safe to consider an alternative ICI if irAE was mild, grade 1 [59].

\section{Tumor Necrosis Factor- $\alpha$ Antagonist Demyelinating Disease}

Tumor necrosis factor- $\alpha$ antagonists (anti-TNFs) are used by rheumatologists, gastroenterologists, and dermatologists for treatment of a broad array of systemic inflammatory diseases $[69,70]$. A host of publications have documented CNS demyelination after anti-TNF treatment including optic neuritis, cerebral, and cord lesions [71]. This may not have been surprising to some after an antiTNF trial for multiple sclerosis was stopped early due to statistically significant increase in relapses possibly indicating a paradoxical proinflammatory effect [72]. Symptoms can start as early as days after first infusion, and average onset between 5 and 18 months is reported in the literature [70,73]. Patients may meet criteria for MS at onset of first clinical event (15-21\%) or go on to meet criteria with continued monitoring $(6 \%)[70,71]$. It is unknown whether antiTNF therapy uncovers a latent predisposition for CNS demyelination, itself causes demyelination or perhaps a combination.

Regardless of the underlying etiology, 3-5 days of $1000 \mathrm{mg}$ of intravenous methylprednisolone or oral equivalent is the first-line treatment [71]. While anti-TNF therapy is almost uniformly discontinued after a demyelinating episode, a cautious risk/benefit discussion is warranted and decisions to discontinue therapy should be made on a case by case basis. Notably, rapidly emerging rheumatologic therapies have enlarged the therapeutic arsenal, enabling 
alternative therapies to be considered even in patients with previously refractory systemic disease.

Lastly, given known potential for further relapses even after anti-TNF discontinuation, patients should be clinically and radiographically monitored similar to a patient suffering idiopathic clinically isolated syndrome [71]. Management with MS disease-modifying therapy may be appropriate in relapsing disease presentations.

\section{Postviral Central Nervous System Inflammatory Disease}

\section{Acute Disseminated Encephalomyelitis and Acute Hemorrhagic Leukoencephalomyelitis}

Acute disseminated encephalomyelitis (ADEM) and its more severe variant acute hemorrhagic leukoencephalomyelitis (AHLE) aka acute necrotizing encephalopathy are monophasic inflammatory syndromes which cause severe injury to the brain and spinal cord. The central nervous system (CNS) inflammation most often occurs in a postinfectious or postvaccinial setting $[74,75]$. Common preceding infections include measles, varicella, and rubella, and there is recent publication of a severe necrotizing variant in the setting of the novel coronavirus disease 2019 (COVID-19) [76,77]. Both viral and bacterial vaccinations may precede the syndrome (Steiner 2015). CNS inflammation is thought to be related to massive immune system response against the inciting infection, rather than a manifestation of the infection itself [75].

While infection can and should be treated appropriately, patients should be treated early and aggressively with high-dose intravenous methylprednisolone 20 to $30 \mathrm{mg} / \mathrm{kg}$ per day, or $1000 \mathrm{mg}$ daily for 3 to 5 days with an oral steroid taper over the ensuing 4-6 weeks [78,79]. For refractory cases, IVIG, $2 \mathrm{~g} / \mathrm{kg}$ divided over 2 to 5 days should be considered and may be given concurrently with steroids. Particularly severe cases, e.g., AHLE or refractory ADEM, should also be treated with early plasma exchange, 5 to 7 treatment courses [79]. Therapeutic hypothermia and decompressive craniectomy have been reported in the literature as techniques to manage severe edema $[80,81]$.

\section{Immune Deficiency Associated Central Nervous System Inflammation}

\section{ADA2 Deficiency Vasculitis}

Mutation in the adenosine deaminase 2 (ADA2) gene encoding for adenosine deaminase 2 protein can manifest with a host of vasculitic and inflammatory features. The mutation was first described in a group of children with ischemic and/or hemorrhagic strokes in the setting of fevers, rash, hypogammaglobulinemia, and polyarteritis nodosa (PAN) [82]. There are now over 60 mutations associated with highly variable age of onset and disease presentation [83•]. Notably, a quarter of cases present before age 1 and three quarters before age 10 , but adult onset is widely reported [83•].

Fifty percent of patients suffer neurological involvement which overwhelmingly presents as small vessel ischemic stroke but may also include hemorrhagic stroke, cranial neuropathies and neuropathic pain [83•]). Small and medium artery vasculitis manifests in skin, gastrointestinal tract, liver, kidney, and heart. 
Immunodeficiency as well as severe hematologic disorders, e.g., cytopenias, are common [84].

Treatment with anti-TNFs is first-line therapy for the neurological disease prevention with the expectation of improvement in inflammatory disease and decreased pathological vascular change [83•]. Importantly, the use of aspirin and other anticoagulants is not recommended given risk of hemorrhagic stroke. Systemically, for non-neurologic manifestations, other than treating fever, antiTNFs are less effective and associated with increased opportunistic infections. Platelet disorders and neutropenia have been reported to improve with rituximab and immunoglobulin treatments [83•].

If initial treatment fails, hematopoietic stem cell therapy (HSCT) has been shown to effectively cure various phenotypic manifestations of ADA2 deficiency in young patients [84-88]. Complications of HSCT include autoimmune disease, and it remains preferential to attempt a trial of treatment with anti-TNF therapy prior to proceeding with HSCT.

\section{CVID-Associated Granulomatous Disease}

Paradoxically, primary immunodeficiency leads to overactivity of the immune system, resulting in autoimmune syndromes [89]. Common variable immunodeficiency (CVID), one of the most common immunodeficiencies, is a group of disorders which manifests as primary hypogammaglobulinemia, IgG levels below $5 \mathrm{~g} / \mathrm{L}$ with low IgA and/or IgM, recurrent infections, poor response to vaccination and propensity towards autoimmunity $[90,91]$.

CVID-associated CNS granulomatous disease can occur as isolated CNS disease or in conjunction with systemic granulomas, affecting women more than men, in children as young as 3 [92]. Patients present with seizures, vision loss, weakness, nystagmus, ataxia, or nonspecific headaches or memory concerns. MRI may demonstrate discrete masses (70\%), white matter lesions $(10 \%)$, or leptomeningeal enhancement (10\%) [92]. Given the syndrome may radiographically and histologically mimic neurosarcoidosis, an evaluation of immunoglobulins is essential during workup as low IgG may lead to this less common diagnosis [93]. Mechanistically, it has been proposed that granulomatous disease may be hastened by IVIG treatment [92].

Regardless, IVIG and steroids are the first line for CNS granulomatous disease, but a host of other immunosuppressive agents and biologics have been reported in the literature with varying degrees of success including infliximab, methotrexate, cyclophosphamide, azathioprine rituximab, and cyclosporine [92].

\section{CTLA-4 Haploinsufficiency with Autoimmune Infiltration (CHAI)}

People with heterozygous germline mutations in the CTLA-4 gene, a negative regulator of the immune system, develop interstitial lung disease and fibrosis via lymphocytic infiltration which can also present in the intestines, liver, spleen, and lymph nodes $[94 \bullet, 95]$. In the central nervous system, the disease manifests as lymphocytic infiltration into CNS parenchyma, cerebritis, causing injury through swelling and direct compression $[95,96]$. The molecular function of CTLA-4 is thought to be regulation of $\mathrm{T}_{\text {regs }}$, and those with impaired CTLA-4 show lower circulating B cells and disrupted $\mathrm{T}$ and B cell homeostasis with T cell hyperactivation $[94 \bullet, 95,97]$. 
While intravenous immunoglobulin therapy may decrease infectious respiratory complications, the lymphocytic infiltrative disease requires immunosuppression, a significant risk in this already immunocompromised population [94•]. Corticosteroid use is the first line for CNS and systemic manifestations but may require high doses and repeated treatments with only variable success $[94 \bullet, 95,97]$. Notably, steroid sparing agents in the literature include rituximab, cyclophosphamide, sirolimus, tacrolimus, mycophenolate mofetil, cyclosporine A, anti-TNFs, 6-mercaptopurine, and methotrexate. Single organ systems may respond to one treatment leaving refractory disease manifestations elsewhere, highlighting the severe refractory course of this disease.

Table 1. Disease-modifying therapies: indications and dosing

\begin{tabular}{|c|c|c|}
\hline Therapies & Indications & Dosing \\
\hline Rituximab & SS, SLE, RA, AAV, IgG-4 RD & $\begin{array}{l}\text { Induction: } 1 \mathrm{~g} \text { IV days } 1 \text { and } 15 \\
\text { Maintenance: } 1 \mathrm{~g} \text { IV q6mo }\end{array}$ \\
\hline Cyclophosphamide & SS, SLE, RA, NS, AAV, NBD & $500-1000$ mg IV monthly for $3-6$ months \\
\hline Azathioprine & SLE, NBD, NS, AAV, IgG4-RD, & $\begin{array}{l}\text { Starting dose: } 50 \mathrm{mg} / \text { day PO or SQ bid } \\
\text { Goal titration: } 2-3 \mathrm{mg} / \mathrm{kg} / \text { day } \mathrm{PO}\end{array}$ \\
\hline Methotrexate & RA, NS, AAV, IgG4-RD & $\begin{array}{l}12-25 \mathrm{mg} P 0 \text { or IV q1wk } \\
\text { For } A A V-0.3 \mathrm{mg} / \mathrm{kg} / \text { day P0 }\end{array}$ \\
\hline Mycophenolate Mofetil & NBD, NS, AAV, IgG4-RD & 750-1500 mg P0 bid \\
\hline Infliximab & $\begin{array}{l}\text { NBD, NS, ADA2 associated } \\
\text { vasculitis }\end{array}$ & $\begin{array}{l}\text { Most indications-starting dose is } 5 \mathrm{mg} / \mathrm{kg} \text { IV } \\
\text { For RA-starting dose is } 3 \mathrm{mg} / \mathrm{kg} / \text { day IV } \\
\text { Induction: } 0,2,6 \text { wk. } \\
\text { Maintenance: q } 8 \text { wk } \\
\text { *Dose can be increase to } 8-10 \mathrm{mg} / \mathrm{kg} \text { and maintenance interval } \\
\text { can be decreased as needed to q6wk }\end{array}$ \\
\hline Adalimumab & NS, NBD & 40 mg SQ q2wk \\
\hline Tocilizumab & NBD & $8 \mathrm{mg} / \mathrm{kg}$ IV q4wk \\
\hline Abatacept & $\begin{array}{l}\text { RA, CTLA- } 4 \text { related } \\
\text { infiltrative disease }\end{array}$ & $\begin{array}{l}\text { SQ dosing } \\
\text { Induction: } \\
\text { - Day 1: } 125 \mathrm{mg} \mathrm{SQ}+10 \mathrm{mg} / \mathrm{kg} \text { IV } \\
\text { - Day 8: } 125 \mathrm{mg} \mathrm{SQ} \\
\text { Maintenance: } 125 \mathrm{mg} \mathrm{SQ} \text { q1wk } \\
\text { IV dosing } \\
\text { Induction: } 10 \mathrm{mg} / \mathrm{kg} \mathrm{IV} \mathrm{on} \mathrm{days} 1,15,29 \\
\text { Maintenance: } 10 \mathrm{mg} / \mathrm{kg} \text { IV q4wk }\end{array}$ \\
\hline Natalizumab & ICI associated AE & 300 mg IV q4wk \\
\hline Immunoglobulin & $\begin{array}{l}\text { SLE, CVID-associated } \\
\text { granulomatous disease }\end{array}$ & $2 \mathrm{~g} / \mathrm{kg}$ IV divided over $3-5$ days $(0.4-0.66 \mathrm{~g} / \mathrm{kg} /$ day) \\
\hline Hydroxychloroquine & SLE & 5 mg/kg/day PO \\
\hline
\end{tabular}


Beyond typical immunosuppressive agents, vedolizumab, an $\alpha 4 \beta 7$ integrin blocker has been shown effective in a case of enterocolitis and severe disease has been treated with hematopoietic stem cell transplantation which may be curative but is high risk [98,99]. Abatacept, a fusion protein of CTLA-4 and the Fc region of IgG1 is approved for treatment of rheumatoid arthritis and represents a rational therapy in this patient population [100]. Two cases demonstrate good response of inflammatory choroiditis and autoimmune hemolytic anemia with GI symptoms in another [101,102]. There is an ongoing trial in the USA to assess the safety and efficacy of abatacept for chronic cytopenias [103] (Table 1).

\section{Compliance with Ethical Standards}

Human and Animal Rights and Informed Consent

This article does not contain any studies with human or animal subjects performed by any of the authors.

\section{References and Recommended Reading}

Papers of particular interest, published recently, have been highlighted as:

- Of importance

1. Kampylafka EI, Alexopoulos H, Dalakas MC, Tzioufas AG. Immunotherapies for neurological manifestations in the context of systemic autoimmunity. Neurotherapeutics. 2016;13:163-78.

2. $\quad$ Bradshaw MJ, Bhattacharyya S, Venna N, Cahill JF. Neurologic manifestations of systemic rheumatologic diseases. In: Rizvi SA, Cahill JF, Coyle PK, editors. Clinical neuroimmunology: multiple sclerosis and related disorders. Cham: Springer International Publishing; 2020. p. 321-42.

Overview of rheumatologic CNS manifestations.

3. Goldstein JM. Neurologic complications of rheumatic disease. Continuum (Minneap Minn). 2014;20:65769.

4. Mitoma H, Manto M, editors. Neuroimmune diseases: from cells to the living brain. Cham: Springer International Publishing; 2019.

5. Shiboski CH, Shiboski SC, Seror R, Criswell LA, Labetoulle M, Lietman TM, et al. 2016 American College of Rheumatology/European League Against Rheumatism Classification Criteria for Primary Sjögren's Syndrome: a consensus and data-driven methodology involving three international patient $\mathrm{CO}-$ horts. Arthritis Rheum. 2017;69:35-45.

6. Massara A, Bonazza S, Castellino G, Caniatti L, Trotta F, Borrelli $\mathrm{M}$, et al. Central nervous system involvement in Sjögren's syndrome: unusual, but not unremarkable-clinical, serological characteristics and outcomes in a large cohort of Italian patients. Rheumatology (Oxford). 2010;49:1540-9.
7. McCoy SS, Baer AN. Neurological complications of Sjögren's syndrome: diagnosis and management. Curr Treatm Opt Rheumatol. 2017;3:275-88.

8. Jobling K, Ledingham D, Ng W-F, Guadagno J. Positive anti-MOG antibodies in a patient with Sjögren's syndrome and transverse myelitis. Eur J Rheumatol. 2019;6:102-4.

9.• Ramos-Casals M, Brito-Zerón P, Bombardieri S, Bootsma H, De Vita S, Dörner T, et al. EULAR recommendations for the management of Sjögren's syndrome with topical and systemic therapies. Ann Rheum Dis. 2020;79:3-18.

Update of systemic SS recommendations.

10. Seror R, Ravaud P, Bowman SJ, Baron G, Tzioufas A, Theander E, et al. EULAR Sjogren's syndrome disease activity index: development of a consensus systemic disease activity index for primary Sjogren's syndrome. Ann Rheum Dis. 2010;69:1103-9.

11. Flores-Chávez A, Kostov B, Solans R, Fraile G, Maure B, Feijoo-Massó C, et al. Severe, life-threatening phenotype of primary Sjögren's syndrome: clinical characterisation and outcomes in 1580 patients (GEAS-SS Registry). Clin Exp Rheumatol. 2018;36(Suppl 112):1219.

12. Konttinen YT, Kinnunen E, von Bonsdorff $M$, Lillqvist $\mathrm{P}$, Immonen I, Bergroth $\mathrm{V}$, et al. Acute transverse myelopathy successfully treated with plasmapheresis and prednisone in a patient with primary Sjögren's syndrome. Arthritis Rheum. 1987;30:339-44. 
13. Cojocaru M, Cojocaru IM, Silosi I, Vrabie CD. Manifestations of systemic lupus erythematosus. Maedica (Buchar). 2011;6:330-6.

14. Bertsias GK, Boumpas DT. Pathogenesis, diagnosis and management of neuropsychiatric SLE manifestations. Nat Rev Rheumatol. 2010;6:358-67.

15. Shaban A, Leira EC. Neurological complications in patients with systemic lupus erythematosus. Curr Neurol Neurosci Rep. 2019;19:97.

16. Hirohata S, editor. Neuropsychiatric systemic lupus erythematosus: pathogenesis, clinical aspects and treatment. 1st ed. New York: Springer; 2018. p. 2018.

17. Holmqvist M, Simard JF, Asplund K, Arkema EV. Stroke in systemic lupus erythematosus: a metaanalysis of population-based cohort studies. RMD Open. 2015;1:e000168.

18. Bucci T, Menichelli D, Pignatelli P, Triggiani M, Violi F, Pastori D. Relationship of antiphospholipid antibodies to risk of dementia: a systematic review. J Alzheimers Dis. 2019;69:561-76.

19. Fanouriakis A, Kostopoulou M, Alunno A, Aringer M, Bajema I, Boletis JN, et al. 2019 update of the EULAR recommendations for the management of systemic lupus erythematosus. Ann Rheum Dis. 2019;78:73645 .

Update of systemic SLE recommendations.

20. Fanouriakis A, Pamfil C, Sidiropoulos P, Damian L, Flestea A, Gusetu G, et al. Cyclophosphamide in combination with glucocorticoids for severe neuropsychiatric systemic lupus erythematosus: a retrospective, observational two-centre study. Lupus. 2016;25:62736.

21. Levine SR, Brey RL, Tilley BC, Thompson JLP, Sacco RL, Sciacca RR, et al. Antiphospholipid antibodies and subsequent thrombo-occlusive events in patients with ischemic stroke. JAMA. 2004;291:576-84.

22. Kalra S, Silman A, Akman-Demir G, Bohlega S, Borhani-Haghighi A, Constantinescu CS, et al. Diagnosis and management of Neuro-Behçet's disease: international consensus recommendations. J Neurol. 2014;261:1662-76.

23. Uygunoğlu U, Siva A. Behçet's syndrome and nervous system involvement. Curr Neurol Neurosci Rep. 2018;18:35.

24. Hatemi G, Christensen R, Bang D, Bodaghi B, Celik AF, Fortune F, et al. 2018 update of the EULAR recommendations for the management of Behçet's syndrome. Ann Rheum Dis. 2018;77:808-18.

25. Bettiol A, Hatemi G, Vannozzi L, Barilaro A, Prisco D, Emmi G. Treating the different phenotypes of behçet's syndrome. Front Immunol. 2019;10:2830.

26. Borhani-Haghighi A, Kardeh B, Banerjee S, Yadollahikhales G, Safari A, Sahraian MA, et al. NeuroBehcet's disease: an update on diagnosis, differential diagnoses, and treatment. Mult Scler Relat Disord. 2019;39:101906.

27. Shapiro LS, Farrell J, Borhani HA. Tocilizumab treatment for neuro-Behcet's disease, the first report. Clin Neurol Neurosurg. 2012;114:297-8.
28. Addimanda O, Pipitone N, Pazzola G, Salvarani C. Tocilizumab for severe refractory neuro-Behçet: three cases IL- 6 blockade in neuro-Behçet. Semin Arthritis Rheum. 2015;44:472-5.

29. Frazao IC, Linford HT, Bronner GE, Massaro CDS, Henning PR. Carotid dissection secondary to neurobehcets disease - case report. J Neurol Psychiatr Disord. 2019;2:1-4.

30. Montecucco F, Mach F. Common inflammatory mediators orchestrate pathophysiological processes in rheumatoid arthritis and atherosclerosis. Rheumatology (Oxford). 2009;48:11-22.

31. Terashima Y, Yurube T, Hirata H, Sugiyama D, Sumi M. Hyogo Organization of Spinal Disorders. Predictive risk factors of cervical spine instabilities in rheumatoid arthritis: a prospective multicenter over 10-year cohort study. Spine. 2017;42:556-64.

32. Servioli MJ, Chugh C, Lee JM, Biller J. Rheumatoid meningitis. Front Neurol. 2011;2:84.

33. Nissen MS, Nilsson AC, Forsberg J, Milthers J, Wirenfeldt $\mathrm{M}$, Bonde $\mathrm{C}$, et al. Use of cerebrospinal fluid biomarkers in diagnosis and monitoring of rheumatoid meningitis. Front Neurol. 2019;10:666.

34. Pellerin D, Wodkowski M, Guiot M-C, AlDhukair H, Blotsky A, Karamchandani J, et al. Rheumatoid meningitis presenting with acute parkinsonism and protracted non-convulsive seizures: an unusual case presentation and review of treatment strategies. Front Neurol. 2019;10:163.

35. Starosta MA, Brandwein SR. Clinical manifestations and treatment of rheumatoid pachymeningitis. Neurology. 2007;68:1079-80.

36. Yücel AE, Kart H, Aydin P, Ağildere AM, Benli S, Altinörs N, et al. Pachymeningitis and optic neuritis in rheumatoid arthritis: successful treatment with cyclophosphamide. Clin Rheumatol. 2001;20:136-9.

37. Chou RC, Henson JW, Tian D, Hedley-Whyte ET, Reginato AM. Successful treatment of rheumatoid meningitis with cyclophosphamide but not infliximab. Ann Rheum Dis. 2006;65:1114-6.

38. Qin Z, Kim J, Valencia D, Hamoodi L, Neltner J, Sizemore T, et al. Rheumatoid meningitis: a case report and review of the literature. Neurol Clin Pract. 2020;10:73-83.

39. Bourgeois P, Rivest J, Bocti C. Rheumatoid meningitis presenting with stroke-like episodes. Neurology. 2014;82:1564-5.

40. Gelfand JM, Bradshaw MJ, Stern BJ, Clifford DB, Wang $\mathrm{Y}$, Cho TA, et al. Infliximab for the treatment of CNS sarcoidosis: a multi-institutional series. Neurology. 2017;89:2092-100.

Case series of infliximab in NS.

41. Voortman M, Drent M, Baughman RP. Management of neurosarcoidosis: a clinical challenge. Curr Opin Neurol. 2019;32:475-83.

42. Bitoun S, Bouvry D, Borie R, Mahevas M, Sacre K, Haroche J, et al. Treatment of neurosarcoidosis: a comparative study of methotrexate and mycophenolate mofetil. Neurology. 2016;87:2517-21. 
43. Kusano KF, Satomi K. Diagnosis and treatment of cardiac sarcoidosis. Heart. 2016;102:184-90.

44. $\quad$ Zheng Y, Zhang Y, Cai M, Lai N, Chen Z, Ding M. Central nervous system involvement in ANCA-associated vasculitis: what neurologists need to know. Front Neurol. 2018;9:1166.

Review and recommendations for AAV.

45. de Boysson H. Central nervous system involvement in ANCA-associated vasculitis. In: Sinico RA, Guillevin L, editors. Anti-neutrophil cytoplasmic antibody (ANCA) associated vasculitis. Cham: Springer International Publishing; 2020. p. 239-49.

46. Stone JH, Merkel PA, Spiera R, Seo P, Langford CA, Hoffman GS, et al. Rituximab versus cyclophosphamide for ANCA-associated vasculitis. N Engl J Med. 2010;363:221-32.

47. Kallenberg CGM. Treatment of ANCA-associated vasculitis, where to go? Clin Rev Allergy Immunol. 2012;43:242-8.

48. Kamisawa T, Funata N, Hayashi Y, Eishi Y, Koike M, Tsuruta K, et al. A new clinicopathological entity of IgG4-related autoimmune disease. J Gastroenterol. 2003;38:982-4.

49. Sekiguchi H, Horie R, Kanai M, Suzuki R, Yi ES, Ryu JH. IgG4-related disease: retrospective analysis of one hundred sixty-six patients. Arthritis Rheum. 2016;68:2290-9.

50. Wallace ZS, Naden RP, Chari S, Choi HK, Della-Torre E Dicaire J-F, et al. The 2019 American College of Rheumatology/European League Against Rheumatism classification criteria for IgG4-related disease. Ann Rheum Dis. 2020;79:77-87.

51. Levraut M, Cohen M, Bresch S, Giordana C, BurelVandenbos F, Mondot L, et al. Immunoglobulin G4related hypertrophic pachymeningitis. Neurol Neuroimmunol Neuroinflamm. 2019;6:e568.

52. van den Elshout-den Uyl D, Spoto CPE, de Boer M, Leiner T, Leavis HL, Leguit RJ. First report of igg 4 related disease primary presenting as vertebral bone marrow lesions. Front Immunol. 2019;10:1910.

53. Ebbo M, Grados A, Samson M, Groh M, Loundou A, Rigolet A, et al. Long-term efficacy and safety of rituximab in IgG4-related disease: data from a French nationwide study of thirty-three patients. PLoS One. 2017; 12:e0183844.

54. Robert C, Schachter J, Long GV, Arance A, Grob JJ, Mortier $\mathrm{L}$, et al. Pembrolizumab versus ipilimumab in advanced melanoma. N Engl J Med. 2015;372:252132.

55. Motzer RJ, Escudier B, McDermott DF, George S, Hammers HJ, Srinivas S, et al. Nivolumab versus everolimus in advanced renal-cell carcinoma. $\mathrm{N}$ Engl J Med. 2015;373:1803-13.

56. Decatris MP, O'Byrne KJ. Immune checkpoint inhibitors as first-line and salvage therapy for advanced nonsmall-cell lung cancer. Future Oncol. 2016;12:180522.

57. Bellmunt J, de Wit R, Vaughn DJ, Fradet Y, Lee J-L, Fong $\mathrm{L}$, et al. Pembrolizumab as second-line therapy for advanced urothelial carcinoma. N Engl J Med. 2017;376:1015-26.

58. Havel JJ, Chowell D, Chan TA. The evolving landscape of biomarkers for checkpoint inhibitor immunotherapy. Nat Rev Cancer. 2019;19:133-50.

59. Postow MA, Sidlow R, Hellmann MD. Immune-related adverse events associated with immune checkpoint blockade. N Engl J Med. 2018;378:158-68.

60. Touat M, Talmasov D, Ricard D, Psimaras D. Neurological toxicities associated with immune-checkpoint inhibitors. Curr Opin Neurol. 2017;30:659-68.

61. Zekeridou A, Lennon VA. Neurologic autoimmunity in the era of checkpoint inhibitor cancer immunotherapy. Mayo Clin Proc. 2019;94:1865-78.

irAE from ICI.

62. LaPorte J, Solh M, Ouanounou S. Posterior reversible encephalopathy syndrome following pembrolizumab therapy for relapsed Hodgkin's lymphoma. J Oncol Pharm Pract. 2017;23:71-4.

63. Williams TJ, Benavides DR, Patrice K-A, Dalmau JO, de Ávila ALR, Le DT, et al. Association of autoimmune encephalitis with combined immune checkpoint inhibitor treatment for metastatic cancer. JAMA Neurol. 2016;73:928-33.

64. Schneider S, Potthast S, Komminoth P, Schwegler G, Böhm S. PD-1 checkpoint inhibitor associated autoimmune encephalitis. Case Rep Oncol. 2017;10:4738.

65. Astaras C, de Micheli R, Moura B, Hundsberger T, Hottinger AF. Neurological adverse events associated with immune checkpoint inhibitors: diagnosis and management. Curr Neurol Neurosci Rep. 2018;18:3

66. Oishi K, Nakao M, Maeda S, Matsushita T, Ikeda T, Yamada $\mathrm{T}$, et al. A case of aseptic meningitis without neck rigidity occurring in a metastatic melanoma patient treated with ipilimumab. Eur J Dermatol. 2017;27:193-4.

67. Larkin J, Chmielowski B, Lao CD, Hodi FS, Sharfman W, Weber J, et al. Neurologic serious adverse events associated with Nivolumab plus ipilimumab or nivolumab alone in advanced melanoma, including a case series of encephalitis. Oncologist. 2017;22:70918.

68. Hottinger AF, de Micheli R, Guido V, Karampera A, Hagmann P, Du Pasquier R. Natalizumab may control immune checkpoint inhibitor-induced limbic encephalitis. Neurol Neuroimmunol Neuroinflamm. 2018;5:e439.

69. Remicade (infliximab) FDA Approval History Drugs.com [Internet]. [cited 2020 Apr 15]. Available from: https://www.drugs.com/history/remicade.html.

70. Kemanetzoglou E, Andreadou E. CNS demyelination with TNF- $\alpha$ blockers. Curr Neurol Neurosci Rep. 2017:17:36.

71. Seror R, Richez C, Sordet C, Rist S, Gossec L, Direz G, et al. Pattern of demyelination occurring during antiTNF- $\alpha$ therapy: a French national survey. Rheumatology (Oxford). 2013;52:868-74. 
72. TNF neutralization in MS: results of a randomized, placebo-controlled multicenter study. The Lenercept Multiple Sclerosis Study Group and The University of British Columbia MS/MRI Analysis Group. Neurology. 1999;53:457-65. https://doi.org/10.1212/WNL.53.3. 457

73. Mohan N, Edwards ET, Cupps TR, Oliverio PJ, Sandberg G, Crayton H, et al. Demyelination occurring during anti-tumor necrosis factor alpha therapy for inflammatory arthritides. Arthritis Rheum. 2001;44:2862-9.

74. Bale JF. Virus and immune-mediated encephalitides: epidemiology, diagnosis, treatment, and prevention. Pediatr Neurol. 2015;53:3-12.

75. Höftberger R, Lassmann H. Acute disseminated encephalomyelitis and acute hemorrhagic leukoencephalomyelitis. In: Chrétien F, Wong KT, Sharer LR, Keohane C (Katy), Gray F, editors. Infections of the central nervous system: pathology and genetics. Hoboken: Wiley; 2020. p. 251-7.

76. Poyiadji N, Shahin G, Noujaim D, Stone M, Patel S, Griffith B. COVID-19-associated acute hemorrhagic necrotizing encephalopathy: CT and MRI features. Radiology. 2020. https://doi.org/10.1148/radiol. 2020201187

77. Steiner I, Kennedy PGE. Acute disseminated encephalomyelitis: current knowledge and open questions. J Neuro-Oncol. 2015;21:473-9.

78. Pohl D, Tenembaum S. Treatment of acute disseminated encephalomyelitis. Curr Treat Options Neurol. 2012;14:264-75.

79. Pohl D, Alper G, Van Haren K, Kornberg AJ, Lucchinetti $\mathrm{CF}$, Tenembaum S, et al. Acute disseminated encephalomyelitis: updates on an inflammatory CNS syndrome. Neurology. 2016;87:S38-45.

80. Granget E, Milh M, Pech-Gourg G, Paut O, Girard N, Lena $G$, et al. Life-saving decompressive craniectomy for acute disseminated encephalomyelitis in a child: a case report. Childs Nerv Syst. 2012;28:1121-4.

81. Miyamoto K, Kozu S, Arakawa A, Tsuboi T, Hirao J-I, Ono K, et al. Therapeutic hypothermia with the use of intracranial pressure monitoring for acute disseminated encephalomyelitis with brainstem lesion: a case report. J Child Neurol. 2014;29:NP69-73.

82. Zhou Q, Yang D, Ombrello AK, Zavialov AV, Toro C, Zavialov AV, et al. Early-onset stroke and vasculopathy associated with mutations in ADA2. N Engl J Med. 2014;370:911-20.

83. Meyts I, Aksentijevich I. Deficiency of adenosine deaminase 2 (DADA2): updates on the phenotype, genetics, pathogenesis, and treatment. J Clin Immunol. 2018;38:569-78.

ADA2 Review.

84. Hashem H, Egler R, Dalal J. Refractory pure red cell aplasia manifesting as deficiency of adenosine deaminase 2. J Pediatr Hematol Oncol. 2017;39:e293-6.

85. Hsu AP, West RR, Calvo KR, Cuellar-Rodriguez J, Parta $\mathrm{M}$, Kelly SJ, et al. Adenosine deaminase type 2 deficiency masquerading as GATA2 deficiency: Successful hematopoietic stem cell transplantation. J Allergy Clin Immunol. 2016;138:628-630.e2.

86. Hashem H, Kumar AR, Müller I, Babor F, Bredius R, Dalal J, et al. Hematopoietic stem cell transplantation rescues the hematological, immunological, and vascular phenotype in DADA2. Blood. 2017;130:2682-8.

87. Van Eyck L, Hershfield MS, Pombal D, Kelly SJ, Ganson NJ, Moens L, et al. Hematopoietic stem cell transplantation rescues the immunologic phenotype and prevents vasculopathy in patients with adenosine deaminase 2 deficiency. J Allergy Clin Immunol.

2015;135:283-7.e5.

88. Navon Elkan P, Pierce SB, Segel R, Walsh T, Barash J, Padeh S, et al. Mutant adenosine deaminase 2 in a polyarteritis nodosa vasculopathy. N Engl J Med. 2014;370:921-31.

89. Gathmann B, Mahlaoui N, CEREDIH, Gérard L, Oksenhendler E, Warnatz K, et al. Clinical picture and treatment of 2212 patients with common variable immunodeficiency. J Allergy Clin Immunol. 2014;134:116-26.

90. Grimbacher B, ESID Registry Working Party. The European Society for Immunodeficiencies (ESID) registry 2014. Clin Exp Immunol. 2014;178(Suppl 1):18-20.

91. Ameratunga R, Brewerton M, Slade C, Jordan A, Gillis $\mathrm{D}$, Steele R, et al. Comparison of diagnostic criteria for common variable immunodeficiency disorder. Front Immunol. 2014;5:415.

92. Najem CE, Springer J, Prayson R, Culver DA, Fernandez $\mathrm{J}$, Tavee J, et al. Intra cranial granulomatous disease in common variable immunodeficiency: case series and review of the literature. Semin Arthritis Rheum. 2018;47:890-6.

93. Neurology minute: special interest: common variable immune deficiency (CVID) [Internet]. [cited 2020 Apr 22]. Available from: http://neurologyminute.aan. libsynpro.com/special-interest-common-variableimmune-deficiency-cvid.

94. Verma N, Burns SO, Walker LSK, Sansom DM. Immune deficiency and autoimmunity in patients with CTLA-4 (CD152) mutations. Clin Exp Immunol. 2017;190:1-7.

Review of pathology in CTLA-4 deficiency.

95. Kuehn HS, Ouyang W, Lo B, Deenick EK, Niemela JE, Avery DT, et al. Immune dysregulation in human subjects with heterozygous germline mutations in CTLA4. Science. 2014;345:1623-7.

96. Lo B, Fritz JM, Su HC, Uzel G, Jordan MB, Lenardo MJ. CHAI and LATAIE: new genetic diseases of CTLA-4 checkpoint insufficiency. Blood. 2016;128:1037-42.

97. Schubert D, Bode C, Kenefeck R, Hou TZ, Wing JB, Kennedy A, et al. Autosomal dominant immune dysregulation syndrome in humans with CTLA4 mutations. Nat Med. 2014;20:1410-6.

98. Slatter MA, Engelhardt KR, Burroughs LM, Arkwright PD, Nademi Z, Skoda-Smith S, et al. Hematopoietic stem cell transplantation for CTLA4 deficiency. J Allergy Clin Immunol. 2016;138:615-619.e1. 
99. Navarini AA, Hruz P, Berger CT, Hou TZ, Schwab C, Gabrysch A, et al. Vedolizumab as a successful treatment of CTLA-4-associated autoimmune enterocolitis. J Allergy Clin Immunol. 2017;139:1043-1046.e5.

100. Orencia (abatacept) FDA Approval History Drugs.com [Internet]. [cited 2020 May 11]. Available from: https://www.drugs.com/history/orencia.html.

101. Shields CL, Say EAT, Mashayekhi A, Garg SJ, Dunn JP, Shields JA. Assessment of CTLA-4 deficiency-related autoimmune choroidopathy response to abatacept. JAMA Ophthalmol. 2016;134:844-6.

102. Lee S, Moon JS, Lee C-R, Kim H-E, Baek S-M, Hwang $S$, et al. Abatacept alleviates severe autoimmune symptoms in a patient carrying a de novo variant in CTLA-4. J Allergy Clin Immunol. 2016;137:327-30.
103. Safety and efficacy of abatacept for treating chronic cytopenia in cytotoxic T-lymphocyte antigen 4 (CTLA4) haploinsufficiency - full text view ClinicalTrials.gov [Internet]. [cited 2020 Apr 17]. Available from: https://www.clinicaltrials.gov/ct2/ show/NCT03733067.

\section{Publisher's Note}

Springer Nature remains neutral with regard to jurisdictional claims in published maps and institutional affiliations. 